\title{
MUNDIALIZAÇÃO DA ECONOMIA, METROPOLIZAÇÃO DO MUNDO Georges Benko*
}

Resumo: A mundialização é um termo que está na moda. Sua origem se encontra na literatura consagrada às firmas multinacionais. Este artigo mostra a diversidade do conceito segundo as disciplinas (economia, geografia, história, sociologia, comunicação, filosofia) e analisa os pontos de vista econômicos. Mundialização e metropolização se desenvolvem ao mesmo tempo; a nova polarização da economia em torno das grandes cidades mundiais é destacada. As conclusões defendem a idéia de uma mundialização "organizada" e de um mercado mundial regulado.

Palavras-chave: Mundialização; Economia geográfica; Ciências sociais; Metropolização.

\section{Introdução}

A mundialização, ou ainda, em termos anglo-saxões, a globalização, muito em voga nos países da América Latina constitui, nos anos 1990, uma das preocupações prediletas dos intelectuais de todas as tendências, sejam eles economistas, sociólogos, geógrafos ou filósofos. Buscaremos revisitar esta noção e argumentar por que a mundialização está cercada de erros conceituais e de falsas explicações.

Dia após dia, "a mundialização", esta fórmula totalizadora, embora enigmática, é levada para os ouvidos de cada um, por aqueles que procuram justificar as dificuldades do período, recorrendo a uma única "causa", que certamente tem nome, porém ininteligível. Além disso, essa noção de mundialização atingiu tal grau de circulação pública que uma análise faz-se necessária, sobre as modalidades da sua construção e dos seus usos, pois estes influem na sua pregnância e merecem ser apreciados pelas suas qualidades epistemológicas (preocupação com a identificação de uma ordem global do mundo conhecivel) e ideológica (racionalização interessada da imagem do mundo).

\section{Em torno da noção de mundialização}

Em primeiro lugar, a mundialização designa a crescente integração das diferentes partes do mundo, sob o efeito da aceleração das trocas, do impulso das novas tecnologias da informação e da comunicação, dos meios de transporte etc. Refere-se, também, a processos muito específicos que, para uns, são um prolongamento de tendências antigas e, para outros, marcam um novo período.

A mundialização e o economista: É a globalização financeira ou, em outras palavras, a integração dos mercados e das bolsas como conseqüência das políticas de liberalização e do desenvolvimento das novas tecnologias da informação e da comunicação; é também a intensificação dos fluxos de investimento e de capital na escala planetária.

0 economista LEVITT (1983) foi o primeiro a introduzir o termo globalização para designar a convergência dos mercados no mundo inteiro. Entretanto, OHMAE (1996) tem o mérito de popularizar a noção no campo da análise econômica. Para ele, a globalização é uma nova etapa no desenvolvimento das multinacionais, a gestão na escala mundial do conjunto das atividades de uma companhia multinacional, em pesquisa e desenvolvimento até a comercialização, passando pela produção. Para a vertente que estuda as global cities (SASSEN, 1991), a globalização financeira acompanha-se do fortalecimento dos grandes centros financeiros e da emergência de cidades globais como Nova York, Londres, Tóquio.

Surgem companhias multinacionais globais (ANDREFF, 1996; MUCHIELLI, 1998) que integram as atividades financeiras, comerciais, industriais e constituem, assim, uma nova etapa no desenvolvimento das firmas multinacionais pela aceleração das fusões e das concentrações em certos setores (telecomunicações, audiovisual, informática etc.). Gera-se um processo de regionalização, graças à constituição de vastas zonas de livre-comércio, no pano de fundo da tríade (KEBABDJIAN, 1994; KEIZER \& KENIGSWALD, 1996), isto é, a organização da economia mundial em torno de três grandes pólos principais de desenvolvimento: América do Norte, União Européia e Japão. Intensifica-se o comércio mundial: desde os anos 1950, as trocas de bens e de mercadorias conheceram um crescimento superior ao das produções nacionais (RAINELLI, 1997). Verifica-se um crescimento fenomenal dos investimentos internacionais, paralelamente à presença cada vez mais notória das firmas transnacionais nas trocas internacionais e na atividade econômica dos paises.

*Université Panthéon-Sorbonne 12, Place du Panthéon, 75231 Paris Cedex 05, França. e-mail: georges.benko@univ-paris1.fr. 
Os fatos são, nesse aspecto, surpreendentes. A CNUCED (1997) estima hoje em cerca de 44 mil o número de firmas transnacionais e em 280 mil o número de suas filiais. 0 montante das vendas dessas empresas atinge cerca de 7 trilhões de dólares e os investimentos diretos são da ordem de 3,2 trilhões de dólares. A sua importância é ainda melhor entendida quando se considera que o Produto Nacional Bruto (PNB) mundial é de cerca de 30 trilhões de dólares.

Não menos surpreendente é o crescimento dos investimentos diretos estrangeiros. Comparado aos anos 1980, esse crescimento vem diminuindo por razões relacionadas com o impacto da crise de 1991-1993 sobre a economia mundial. Mas a taxa de crescimento dos investimentos diretos estrangeiros mantém uma média muito superior à do comércio internacional e, por conseguinte, à da produção mundial; por outra parte, há, desde 1985, uma nítida aceleração, fenômeno que não pode ser dissociado da abertura maior dos mercados nem da atração exercida pelo forte crescimento econômico dos países ditos "emergentes".

As companhias transnacionais são responsáveis por dois terços do comércio mundial, do qual um terço representa o comércio no interior das empresas. Como reflexo dessa nova realidade, essas firmas ${ }^{1}$ estão no centro da atividade econômica dos paises. Esses dados mostram bem que a mundialização econômica começou mesmo uns vinte anos atrás. Os resultados, porém, são discutidos: para alguns economistas, a conseqüência seria uma tendência à convergência das políticas econômicas nacionais, para outros, seria uma intensificação da interdependência das economias nacionais...

A mundialização e o geógrafo: Para o geógrafo, a mundialização é a "globalização" ou a articulação ampliada dos territórios locais com a economia mundial.

Originalmente, este neologismo foi imposto por diretores japoneses para designar um modo de gestão, ao mesmo tempo global e local, da empresa-rede no quadro da economia mundializada. Em geografia, a noção de globalização é uma maneira de sublinhar a persistência de um registro espacial de fenômenos econômicos - a localização dos locais de produção de uma empresa multinacional nos territórios. Refere-se também à constituição de uma "economia em arquipélago", segundo a expressão figurada de Pierre VELTZ (1996), ou à emergência, na escala planetária, de um "arquipélago megalopolitano mundial", organizado em torno das megalópoles norte-americanas e do sudeste asiático.
A mundialização e as políticas: para as relações internacionais, é o fim da bipolaridade. No tempo da Guerra Fria, o mundo era apreendido em termos de relações Leste-Oeste, Norte-Sul. 0 uso da noção mundialização marca uma mudança de contexto.

Acentuam-se os fenômenos da transnacionalidade e da interdependência. A transnacionalidade se expressa por meio dos atores organizados em redes: multinacionais, diásporas, seitas. Desde os anos 1970-80, a interdependência dos Estados foi particularmente sentida no domínio do meio ambiente. Podem ser integrados, também, fenômenos mais ou menos antigos: as guerras "mundiais", a constituição de uma ordem internacional mediante a criação da Organização das Nações Unidas (ONU), ou mais recentemente, a mundialização.

A mundialização e o historiador: Para o historiador: é uma nova etapa no desenvolvimento de um processo plurissecular: o capitalismo...

É a extensão das "economias-mundo", que foram descritas por BRAUDEL, na sua monumental Civilisation matérielle et capitalisme (1967-1979). Trata-se de áreas de desenvolvimento que se sucederam a partir do século XVI, ao ritmo das grandes descobertas e das inovações técnicas. 0 seu denominador comum: a existência de centros decisórios que organizam as regiões periféricas em função de uma divisão do trabalho e das produções. Apoiando-se nos trabalhos de BRAUDEL (1967), alguns consideram que a mundialização perfaz a constituição de um sistema ou espaço-mundo.

Sabe-se, por exemplo, que BRAUDEL (1988), na sua obra La dynamique du capitalisme, teve a ambição de relacionar 0 capitalismo, a sua evolução e os seus meios, a uma história geral do mundo. Ensinando a distinguir entre economia mundial (economia do mundo tomado no seu todo) e economiamundo (Welwirtschaft: economia de uma parte do nosso planeta, na medida em que ela forma um todo econômico como, por exemplo, o Mediterrâneo do século XVI), BRAUDEL lega esta revisão conceitual a WALLERSTEIN (1974), que, por sua parte, na L'Économie-monde moderne, defende a idéia de uma contradição interna a esse conjunto, na qual participam os "movimentos anti-sistêmicos", isto é, os movimentos sociais de resistência ao desenvolvimento de uma única economia de mercado. Esse quadro estende-se no espaço e integra os impérios-mundos circunvizinhos, sem limites espaciais intrínsecos. "Dessa maneira, pela primeira vez na história do planeta, chegou-se a um momento em que existia apenas um único sistema histórico" (WALLERSTEIN, 1974: 264), enraizado porém

1 Como meu objetivo não é um debate sobre as definições, utilizo aqui duas expressões, "companhias transnacionais" e "companhias multinacionais", de maneira equivalente. 
em contradições. "0 mundo" é uma forma de sintese de movimentos cujos interesses são contrários e que não se localizam dentro de um mundo, porém moldam sua imagem.

A mundialização e o sociólogo: Mundialização da sociedade é a convergência dos modos de vida. No plano cultural, é a difusão de uma cultura universal planetária (por meio de marcos emblemáticos: como Coca-Cola, Disney, os Jogos Olímpicos...), paralelamente a processos de "hibridização", de mestiçagem (até de "crioulização") dos modos de expressão cultural de dimensão universal, fazendo empréstimos a partir das culturas locais, re-apropriados depois, por estas mesmas culturas.

Segundo o sociólogo GIDDENS (1990), o tema da mundialização é abordado em dois tipos de obra singularmente diferentes. As primeiras tratam das relações internacionais, e as outras, das "teorias do sistema mundial", em parte na esteira de WALLERSTEIN (1974), bastante próximo das posições marxistas. GIDDENS (1990) fornece uma análise coerente da mundialização, associando-a à modernidade e ao fim da pós-modernidade.

A mundialização e a comunicação: A mundialização das comunicações e das técnicas é o tecnoglobalismo, isto é, a fusão, em um mesmo saber, de inovações e tecnologias emanando de numerosos territórios, o estabelecimento de um "macro-sistema-técnico" nos transportes, na produção, na comunicação. É também a revolução das comunicações com o desenvolvimento das telecomunicações, dos meios de transmissão (cabos, satélites), a expansão da Internet.

A fórmula "aldeia planetária", forjada em 1962 pelo canadense McLUHAN na sua obra A galáxia de Gutenberg, exprime uma volta ao tribalismo na era da eletricidade e da eletrônica. Enquanto a tipografia teria favorecido o individualismo, as novas mídias levariam ao isolamento dos grupos familiares e sociais. $A$ transmissão simultânea das informações para os quatro cantos do planeta transforma cada telespectador ou ouvinte em um membro da "aldeia planetária". Embora a expressão tenha tido muito sucesso na mundialização, o superpoder das mídias que ela supõe (determinismo tecnológico) tem sido relativisado.

A mundialização e o filósofo: para os filósofos, é a universalidade dos valores. Não é raro encontrar, nos escritos filosóficos, um neologismo significativo à "mundialidade" utilizado às vezes no sentido da universalidade vivenciada. Enfim, lembremos que o Projeto de paz perpétua de Kant constitui uma referência obrigatória, no domínio das relações internacionais e da reflexão, sobre a possibilidade de um governo mundial.

Seria necessário, portanto, fingir acreditar que a "mundialização" não corresponde a nenhum acontecimento, a nenhum processo histórico em curso, e que essa ficção cobre apenas uma realidade que não mudou ou foi mal apreciada? De maneira alguma. Quaisquer que sejam as estratégias do vocabulário, o uso e a difusão da noção de "mundialização" amplificam-se de maneira incontestável na ocasião das transformações sociais e das políticas que precisam ser nomeadas e entendidas corretamente, em virtude do seu peso na transformação e do seu peso moral nas mentes desestabilizadas.

Cabe trabalhar o conceito, tanto na sua extensão quanto na sua compreensão. Além disso, a questão decisiva que deverá ser resolvida é saber como se pode invocar, com pertinência, uma noção de mundo cujas origens filosóficas são tão evidentes. Insistiremos brevemente nesse ponto da teoria filosófica: quem questiona o "mundo" não pode esquecer que está presumindo, por aí, o horizonte de uma totalidade cujo conteúdo deve ser estável no seu conjunto. Voltemos pois, à mundialização. $\mathrm{Na}$ maioria dos casos, o uso muito particular da noção de "mundo" refere-se mais à sobrevivência de uma teoria metafísica na qual as coisas do mundo estão relacionadas entre si por um encadeamento. À semelhança das ciências da natureza e da filosofia clássica das quais procede essa noção, o "mundo" (até o universo, se admitimos a equivalência de pan em grego e de mundis em latim), reporta-se a um modo de reunião e de composição das partes constitutivas do universo. 0 "mundo", fosse ele antes físico, apresenta-se como um edifício de arquitetura perfeita, no qual o olho treinado deve poder discernir uma ligação sistemática.

A fortiori, nenhuma intelecção do fenômeno "mundialização" é possivel sem aprender a designar as dinâmicas históricas do fenômeno, as energias sociais que o atravessam, os conflitos políticos que imprimem nele as suas formas atuais. Ora, esses movimentos, constitutivos do mundo social e histórico atual, se conseguirmos discerni-los, não podem nos levar a duvidar dos jogos de forças e cacifes que devem ser detectados. Tal como o historiador faz presunções, na sua pesquisa sobre as potências imanentes em jogo nas relações sociais, o analista da situação mundial atual deve tentar trazer à luz as fontes a partir das quais decorrem os movimentos observados.

\section{A mundialização e as mitologias}

Um termo que encerra os debates, de maneira abrupta, será útil para o conhecimento das relações sociais contemporâneas? Um termo espetacular, imposto, no centro de toda e qualquer análise? Este termo é a "mundialização", em parte noção, em parte imagem, que leva à representação de uma totalidade sem diferenças - o mundial - destinada a dar a chave de todos os fenômenos econômicos, desde os mais dramáticos (desemprego, exclusão) até os mais apreciados 
nesse plano (os ganhos financeiros dos golden boys). Consideramos essa situação como uma arrogância cega. Mas o recurso à noção de "mundialização" é formulado essencialmente como um álibi e desvia e esconde ora uma certa preguiça do pensamento, ora um desconhecimento global do fenômeno.

Decerto convém, para não dizer que é imperativo, tentar compreender a lógica de um certo estado do mundo atual, em particular quando se deseja ajustar, pertinentemente, as reações que se impõem. Entretanto, com a "mundialização", convoca-se, a despeito das regras conceituais mais elementares, uma causa única, ainda que sem consistência.

A aplicação da noção de causalidade - abstraída do contexto das ciências da natureza e encarada como um modelo explicativo - a fenômenos sociais e históricos não é evidente, pois o recurso a uma causalidade de tipo mecânico - todo fenômeno tem uma causa, um efeito determinado e é produzido de uma única maneira - implica a contigüidade entre o motor e o fenômeno. Em outras palavras, uma causa mecânica define uma relação mecânico-produtiva segundo a qual tudo o que acontece supõe, antes, algo que o origina seguindo uma regra. Nenhum fenômeno pode limitar-se apenas a um sistema mecânico de causalidade, quer sumariamente, porque as causalidades são sempre desdobradas (e em interação), até "sobredeterminadas", quer mais adequadamente, já que todo fenômeno histórico depende de um processo de gestação específica, sem nenhuma analogia com os fenômenos da natureza. "Processo" é entendido, aqui, como função ativa , cuja consistência resulta de estruturas e conjunturas, e cuja eficácia é afetada por conflitos entre interesses opostos.

Quanto à invocação de uma causa única, só é possivel se desprezarmos completamente as relações de forças contraditórias que estruturam os corpos sociais e as relações internacionais. A dinâmica distintiva dos corpos sociais (nacionais ou mundiais) proibe que se considere os eventos de outra maneira senão em referência a uma cristalização, no tempo e no espaço, de relações, situações ou tendências divergentes. Um fenômeno social, qualquer que seja a sua amplitude, somente pode ser compreendido relacionando-o com o jogo das forças das sociedades que formam a substância da sua realidade. Reportar uma série de fenômenos de horizontes diferentes à "mundialização", sem pensar na lógica das instâncias das quais eles dependem, explica tão pouco quanto designar a imigração como a primeira causa do desemprego.

Além disso, a mundialização não designa nenhuma força social precisa nem desvela nenhuma responsabilidade; tampouco amarra nenhuma intenção a uma relação social clara ou pertinente, a partir da qual um encorajamento, um domínio ou, ao contrário, uma oposição poderia ser pensada. Essa "causa" não funciona, portanto, apenas como causa primeira e única e não tem nenhuma consistência.

É por isso que podemos perguntar se a expressão "a mundialização" - no sentido "a culpa é da..." - não faria o papel de uma simples ficção política e econômica. Poder-se-ia, a esse respeito, falar pertinentemente de "mito" contemporâneo, desde que se precise que a função política do mito, no sentido moderno do termo, é a de produzir uma falsa evidência explicativa a partir da invocação de uma natureza ou destino.

BARTHES, nos anos 1960, lembrava que o mito (moderno) não esconde nada, não exibe nada, porém deforma. Não convém acreditar que o mito, do qual temos nesse caso uma figura específica - a da mundialização - constitui uma mentira. 0 mito contribui, mais exatamente, a definir uma inflexão do discurso cujo princípio visa transmutar a história em natureza. Na sua narrativa constitutiva, as palavras se parecem com imagens. Vêm substituir os conceitos que se poderiam esperar do discurso explicativo e são percebidas como sistemas indutivos. No mito "da mundialização", "mundial" aparece como um sistema de fatos dados, o conceito de "mundo" é naturalizado e o resultado é que se espera da "mundialização" que explique os acontecimentos atuais e até mesmo o estado do mundo contemporâneo.

Por conseguinte, não é de se estranhar que "a mundialização" produza tantos consentimentos voluntários, tantas adesões implícitas, mesmo com significados divergentes. Alguns, por exemplo, transformam a "mundialização" em uma saída para seus próprios impasses teóricos, mostrando, de passagem, como o mito fabrica uma palavra "despolitizada". Uma vez que, nesse quadro, os acontecimentos perdem a sua relação com alguma fonte e a sua função em processos determinados, o mundo parece ingressar em uma espécie de complô planetário, no qual e pelo qual seríamos ultrapassados.

Outros passam da tese do complô para a diatribe da denúncia dos "autores" desse complô, versão contemporânea do bode expiatório, especialidade da extrema direita - há muito tempo! Os responsáveis da extrema direita chegaram a associar, em bloco, a mundialização e seus efeitos "diabólicos" com uma "conspiração mundial" (Libération, 15/03/1997).

Basta, porém, recolocar, por um instante, o termo "mundialização" em um discurso mais amplo, para avaliar melhor 0 esvaziamento do real operado pelo mito. Imaginemos a falsa clareza produzida por uma mundialização que reveste a forma de um destino e cujo caráter constrangedor incontornável continua sendo o aspecto imediatamente perceptível. A nova 
ordem do mundo não teria outro significado senão o de propagar as ordens irrevogáveis de alguma potência que determinaria o rumo dos acontecimentos sem que o homem tenha a sua parte de responsabilidade. Entende-se por aí como essa proposta visa essencialmente fabricar uma aceitação relativa dos "declínios" ou dos "fins" constatados ("fim" da história, dos Estados-nações, até das sociedades em benefício das "redes", etc.). Entretanto, o curioso é que esse mesmo destino pode reverter-se, quase por milagre, em discursos completamente opostos. Nesse caso, aceitamos de bom grado uma mundialização que deveria nos salvar da crise pela dupla proximidade de uma sociedade rica em relações mundiais (versão Internet das redes flexíveis, distribuindo a "liberdade") e de uma "sociedade planetária". Na verdade, a submissão ao destino e o encanto pelo milagre depende mais da nossa posição social em relação aos acontecimentos citados ou comentados: pânico frente aos acontecimentos que parecem ultrapassar-nos, ou lirismo aprovador frente a acontecimentos que nos satisfazem (uma estratégia, uma carreira).

\section{As questões econômicas}

A mundialização não é de fato, uma novidade: Para os economistas e a maioria dos pesquisadores em ciências sociais, as análises retrospectivas referem-se, no máximo, a um período de uma a duas décadas. Nesse horizonte, não há duvida de que a economia internacional tenha registrado transformações consideráveis. 0 diagnóstico, porém, é bem diferente se considerarmos o tempo longo do capitalismo. Os anos 1990 são novos em relação aos anos 1960, embora numerosas características contemporâneas já pudessem ser observadas na véspera da Primeira Guerra Mundial.

No comércio e investimentos diretos no exterior, o grau de abertura das economias industrializadas é hoje quase equivalente ao que era no início deste século. Particularmente dinâmico, o investimento financeiro é sempre direcionado para os países emergentes: a Rússia e os países latino-americanos nos anos 1900, a Ásia nos dias atuais. 0 desenvolvimento das telecomunicações, ontem o telégrafo, hoje o satélite e a rede Internet, permitem propagar as notícias, de um mercado financeiro para outro, muito mais rapidamente que no passado. 0 desmoronamento dos regimes comunistas denota, também, uma configuração européia, e certas estratégias nacionais que lembram o contexto do início deste século (BOYER et al., 1997). Seria errôneo, entretanto, deduzir a partir daí a identidade das configurações do regime internacional, pois a história raramente se repete de maneira idêntica.
Recentemente, desenvolveram-se zonas econômicas que têm o mérito e o objetivo de tentar tirar o melhor proveito das interdependências estratégicas entre diversos domínios e países, cujos interesses podem transitoriamente divergir. É irônico que o tema da globalização apareça logo no momento em que se constituem três grandes zonas econômicas: Nafta na América do Norte, a União Européia e uma integração econômica de fato, da Ásia do Sudeste, no quadro institucional flexível e pouco coercivo do Asean. 0 projeto da moeda única européia pode, pois, ser interpretado como a expressão da vontade dos governantes de contornar a inexistência de um sistema financeiro internacional coerente e de ter algum peso nas negociações que estão por vir sobre um sucessor ao sistema de Bretton Woods. Quanto ao "Grande Mercado Europeu", o projeto inicial de Jacques Delors visava consolidar o estilo das instituições nacionais, marcadas por um Estado intervencionista e uma cobertura social ampliada, e liberar-se parcialmente dos áleas e dos choques vindos do resto do mundo. 0 termo globalização deveria então ser substituído por "triadisação", que OHMAE (1996) contribuiu a lançar! Embora não seja mais feliz, o termo, ao menos, é mais fiel às tendências em jogo.

Enfim, última ironia, o agravamento dos déficits públicos, observado nos anos 1970 e 1980, incentivou os Estados a uma nova descentralização e a uma regionalização da gestão dos bens coletivos locais, tais como as infra-estruturas de transporte, da educação, da formação e até mesmo os auxílios ao desenvolvimento e à inserção social dos desempregados. Descobre-se, então, que a densidade das relações entre os atores locais (empresas, municipios, universidades, centros de pesquisa, sindicatos) pode ter um papel determinante na competitividade de determinadas atividades industriais e serviços. Os distritos industriais italianos parecem ter o seu equivalente no BaddenWürttenberg, assim como em certas prefeituras japonesas.

0 neologismo já invocado, a "globalização", expressa, ao seu modo, essa sutil sinergia entre instituições locais infranacionais e a competitividade tão apreciada nos mercados internacionais. 0 espaço das regiões ou, ainda, das grandes aglomerações permite, em parte, a reconstrução de algumas instituições econômicas que durante os anos fordistas eram exclusivamente nacionais.

0 entrelaçamento desses diversos determinantes é tão complexo que a maioria dos tomadores de decisões privados e políticos preferiram, logicamente, o conceito errôneo, mas simples, de globalização àquele mais pertinente, porém complicado, da ordem "entrelaçada". 0 que não é motivo para que analistas e pesquisadores façam o mesmo, pois, cedo ou tarde, os limites da configuração atual levarão a uma redefinição de 
uma ordem internacional digna desse nome. Onde está, porém, o economista e diplomata tão talentoso quanto John Maynard Keynes que terá a audácia de imaginar, de negociar, para depois implantar, um verdadeiro substituto ao sistema do pós-Segunda Guerra Mundial (BOYER et al., 1997)?

Rumo a um sistema produtivo mundial integrado: A transnacionalização das empresas não é mais um fenômeno novo. Esse fenômeno enraíza-se na própria dinâmica do capitalismo, como Marx já o destacava há 150 anos! Entretanto, foi, sobretudo no período pós-guerra que o processo se desenvolveu, principalmente sob o impulso das empresas americanas e no novo contexto da liberalização institucionalizada das trocas. É claro que, ainda hoje, as firmas americanas estão no centro do fenômeno, assim como os Estados Unidos ainda são o principal país de origem dos investimentos diretos no exterior. A prova, muito eloqüente, é que, segundo a Cnuced, as cinco maiores empresas transnacionais americanas controlariam 19\% dos investimentos diretos no exterior; as dez primeiras, 33\%; e as cinqüenta primeiras, 63\%; ou, ainda, o fato de que um quarto dos investimentos diretos no mundo são originários dos Estados Unidos. Também é claro, ainda hoje, que conquanto exista uma relação muito estreita entre os investimentos e o comércio, existe paralelamente uma relação entre a localização geográfica dos investimentos e o nivel de desenvolvimento dos mercados. Entretanto, essas realidades não devem levar-nos a menosprezar o fato de que, se o fenômeno de transnacionalização das empresas possui a sua própria dinâmica, tal dinâmica está alimentada pelo ambiente econômico do país de origem tanto quanto pelo do país receptor (DUNNING, 1996). De fato, esse processo encontra a sua finalidade e a sua razão de ser tanto na maneira como as empresas aproveitam as diferenças existentes entre as economias nacionais quanto na maneira como elas organizam e dividem as atividades entre as diversas unidades de produção que compõem as suas redes. Observa-se aqui, no nível da economia mundial, o que pode ser chamado uma dialética da homogeneização e da diferenciação.

Para resumir, o que está sendo implantado é um sistema de produção cada vez mais integrado na escala mundial. Essa evolução seria associada a duas causas: a primeira dever-se-ia ao fato de que as unidades componentes do sistema - no caso, as diversas filiais dos grupos transnacionais - estão interconectadas em redes, cada filial encontrando o seu lugar no sistema, em função da aplicação de estratégias cada vez mais globais de gestão, produção e investimento por parte dos grupos dominantes. A segunda causa é imputada às redes cada vez mais e mais complexas, cujas fronteiras e alcance das operações são também cada vez mais difíceis de ser apreendidas, sobretudo porque essas redes se cruzam e embaralham. Partindo desses elementos, podemos tirar três conclusões principais: primeiro, tudo acontece como se as empresas estivessem reproduzindo, na cena internacional, o mesmo modelo de integração corporativa que aquele encontrado outrora dentro das fronteiras nacionais; segundo, as modalidades de integração das economias nacionais com a nova economia mundial estão cada vez mais determinadas pelo lugar que as empresas multinacionais irão ocupar dentro desse sistema de produção internacional; e, por fim, com a emergência do novo modelo de organização da produção na escala mundial, estaríamos assistindo, paralelamente, à emergência de um novo modelo de integração econômica internacional. Esse modelo é qualificado pela Cnuced como integração "profunda" (deep integration), para melhor distingui-lo do modelo anterior qualificado como integração "superficial" (shallow integration), uma vez que estaríamos passando de uma integração pelo comércio para uma integração pelas cadeias de produção (e de valor).

Embora a nova realidade representada pela globalização ainda seja "percebida de maneira confusa", não impede que a transnacionalização crescente das atividades das empresas modifique completamente a natureza das relações entre os Estados e a forma da integração dos diversos espaços econômicos que a compõem.

Portanto, essas novas tendências impelem fortemente para a uma reforma profunda dos quadros normativos que regeram até então as trocas internacionais. 0 caminho, entretanto, que deve levar a tal reforma está longe de ser tão linear quanto o deixa acreditar uma certa concepção funcionalista da cooperação econômica internacional. De fato, não somente devemos levar em consideração que os Estados são solicitados por duas forças contraditórias, as que emergem do próprio sistema econômico internacional e as que emergem do papel que devem ter em relação à sua própria sociedade civil, como devemos, também, considerar as interações complexas que se tecem entre as estratégias pró-competitivas usadas pelos governos para assegurar o crescimento em uma economia aberta e as usadas pelas empresas para assegurar a sua própria rentabilidade dentro do sistema mundial. Por sua vez, esse sistema, ao tornar-se mais aberto, oferece uma margem maior de liberdade para as firmas multinacionais.

Paul Krugman e o comércio internacional: 0 debate, porém, não pára por aí. As contribuições maiores de Krugman, especialista americano do comércio internacional, fazem desaparecer os clichês muito simplistas e espalhados, tanto na direita como na esquerda, sobre a mundialização e os males 
econômicos e sociais que Ihe são atribuídos. Ele demonstra que a economia mundial é um sistema complexo de relações cujos efeitos são retroativos, e não um encadeamento de causas mecânicas em sentido único. Fiel seguidor de Ricardo e de Turgot, ele se revolta contra os incultos da economia e as suas teorizações "pop" (segundo a denominação krugmaniana), causadores de estragos. Entre esses ignorantes, encontram-se numerosos autores de best sellers, como Robert Reich, exconselheiro de Clinton, Lester Thurow ou, ainda, John Sculley. Ao qualificar os manuais sobre o comércio internacional de "tecidos de inépcias", ele levanta nas suas obras os erros mais difundidos, em seis pontos, que resumirei: 1) a mundialização e a abertura das economias são um fenômeno antigo, ao contrário do que se acredita geralmente; 2 ) somente as empresas estão em concorrência e não os Estados; 3) a produtividade elevada é uma boa coisa, permite produzir mais e, por conseguinte, consumir mais; 4) a conquista dos setores com alto valor agregado é uma estratégia idiota, devendo um país deixar que lhe sejam impostas as atividades para as quais os seus habitantes são mais dotados; 5) o comércio internacional tem uma fraca incidência sobre 0 emprego; 6 ) a mundialização não tem praticamente nenhuma influência na escala das rendas. Krugman está convencido de que o verdadeiro problema da distribuição das rendas encontra-se no interior dos paises e não entre eles. Isso é particularmente verdadeiro no Brasil. Embora aprove numerosas idéias de Krugman, citarei apenas um número para refletir sobre a desigualdade mundial: o presidente da Disney (M. Eisner) ganha, por hora, mais do que um habitante do Haiti durante dezesseis anos.

\section{A reorganização do espaço mundial: a metropolização}

Uma observação preliminar. 0 novo ministro do Planejamento do Território na França, Dominique Voynet (do Partido Verde), adotou em 1998 uma estratégia diferente daquela dos seus predecessores. Tradicionalmente, as medidas de planejamento do território concediam compensações para as zonas rurais isoladas ou para as regiões economicamente sinistradas. A ministra quer romper com esta visão ruralista, considerada por ela como assistencial, ou de migalhas clientelistas, e "favorecer a emergência de novos pólos de desenvolvimento a partir das aglomerações". "A ajuda econômica e os programas de infra-estrutura" deveriam doravante ser dirigidos, principalmente, para as cidades que concentram $80 \%$ da população, para que cumpram, mais intensamente e melhor, o seu papel de impulso em relação às zonas peri-urbanas e às cercanias rurais.
A nova lei de planificação deveria, pois, reconhecer o papel motor das aglomerações na redução das desigualdades territoriais. Quando falamos da economia mundial, pensamos espontaneamente em um mosaico de economias nacionais que fazem trocas entre si, são concorrentes, convergem e divergem. Ora, essa imagem não é nem falsa, nem completamente correta. A "mundialização" está longe de apagar o fato nacional. 0 único mundo realmente globalizado é o da finança. Na economia real, estamos ainda muito longe de um mercado mundial unificado e homogêneo (ainda não é o caso na Europa, depois de décadas de construção do mercado dito "único"!). Quanto aos Estados, eles continuam tendo um papel crucial, nem que seja por causa dos investimentos na formação dos homens, nas infra-estruturas de transporte e na proteção social.

Por outra parte, a mundialização corresponde, de certo, a uma transformação profunda da economia em mosaico de nações. A explosão, desde 1985, do investimento direto no exterior levou à criação de vastas redes transnacionais de produção e não mais apenas às trocas. Duas constatações esclarecem a lógica das novas estruturas. Por um lado, o papel crescente das relações de proximidade. Com a queda regular de todas as barreiras nacionais, entre outras, pela redução dos direitos alfandegários, constata-se uma volta da geografia no sentido ordinário do termo. As relações de proximidade adquirem um papel mais importante em todas as escalas. Por exemplo, com a queda do muro de Berlim, a Europa descobre-se novamente não somente como uma entidade social e histórica, mas como uma entidade geográfica. Percebe-se que Praga ou Varsóvia são muito próximas dos centros industriais do oeste. As geografias centradas sobre as bacias marítimas reaparecem, e o mar continua sendo o meio de transporte, de longe, menos oneroso. Novos "Mediterrâneos" formam-se, como na Ásia do leste.

A segunda constatação é a "metropolização" da economia mundial. Todos os observadores concordam neste fato: 0 crescimento, a potência e a riqueza estão cada vez mais concentrados em um número limitado de grandes pólos. A produção de Tóquio corresponde a cerca de duas vezes a do Brasil; a de Chicago pode ser comparada à do México e, neste país, pelo menos a metade da atividade está concentrada na sua capital. 0 orçamento do departamento dos Hauts de Seine (oeste de Paris) equivale ao da Bélgica. Os exemplos poderiam ser multiplicados ao infinito. 0 desenvolvimento das metrópoles é que puxa as economias. As trocas ocorrem menos entre as nações do que entre esses pólos que tendem a organizar-se em redes, como uma economia de arquipélago, onde as zonas intermediárias são cada vez mais ignoradas. 
Para entender o papel das grandes cidades no tempo da mundialização, a oposição clássica cidade-campo torna-se menos pertinente do que aquela muito utilizada por BRAUDEL: a oposição entre as economias "urbanas" e as economias "territoriais". As cidades, como todos sabem, geraram e abrigaram os primeiros êxitos capitalistas. As economias urbanas, freqüentemente ligadas às redes marítimas, eram economias muito mais ágeis do que as economias territoriais em construção que tinham de enfrentar a terrivel resistência das distâncias terrestres para o deslocamento dos homens e dos bens. Pode-se, pois, opor as "cidades-mundos" de BRAUDEL (1967) e as economias compactas, como a da Holanda do século XVII, às economias da França ou da Espanha, onde a laboriosa construção do Estado não pode ser dissociada do controle de territórios muito estendidos. Porém, com o advento do capitalismo industrial, a economia nacional digeriu completamente as economias urbanas. Esse processo terminou recentemente na França, onde uma economia nacional integrada constituiu-se, essencialmente, depois da guerra. Foi durante esse periodo que a economia parisiense decentralizou-se e as indústrias deixaram a capital para espalhar-se no território.

Ora, podemos nos perguntar se não estamos entrando atualmente em um novo ciclo das economias "urbanas". Alguns indícios sobre essa questão merecem uma reflexão. 0 primeiro é a já mencionada concentração espacial dos focos de crescimento. 0 desenvolvimento espetacular da China, por exemplo, concentra-se em alguns pólos litorâneos. 0 êxito das cidades-estado, como Cingapura ou Hong-Kong, é surpreendente. A metropolização da economia é um processo comum a todos os países desenvolvidos. Apesar de todos os esforços em matéria de descentralização na França, Paris não somente manteve o seu lugar na economia nacional como ainda cresceu. Na Grã-Bretanha, a metrópole londrina estende-se por todo o conjunto do sudeste. No Japão, a estrutura urbana, que era multipolar, torna-se cada vez mais monopolar, em torno de Tóquio. Ainda poderíamos evocar o caso dos países do terceiro-mundo cuja "macrocefalia" atinge às vezes proporções extravagantes, ainda que para isso sejam necessárias lógicas muito diferentes.

Um segundo indício é a desconexão crescente entre a economia dos centros e a das periferias. Todos lembramos da representação geográfica da França na estrutura piramidal das regiões, dos departamentos, dos distritos (arrondissements), dos centros dos cantões. Nessa representação, o destino da periferia está associado ao destino do centro. Se a capital for dinâmica, difunde riquezas para a periferia. Em sentido inverso, a periferia nutre a capital (no sentido próprio e figurado). Ora, essa representação é cada vez mais falsa. Hoje, em vez desse esquema "vertical" (como as bonecas russas), instaura-se um sistema "horizontal", em que os grandes pólos estão cada vez mais acoplados diretamente entre si. 0 trem de grande velocidade reuniu as economias de Paris e de Lyon. Os efeitos positivos, porém, pouco se fizeram sentir em Mâcon ou em Dijon. Toulouse é hoje uma cidade muito dinâmica inserida numa região que não é dinâmica. Na realidade, a sua economia está estreitamente associada à de Paris. 0 que é verdadeiro na escala nacional também o é na escala internacional. Os fluxos que crescem mais rapidamente na Europa são, de longe, os fluxos entre capitais.

0 que acontece, nesse contexto, com a solidariedade entre territórios? É uma questão essencial. Se as periferias estão em parte desconectadas da economia das grandes cidades, o seu destino continua associado a elas, pelo viés das redistribuições estatais. Alguns dirão que essas periferias, hoje, pesam mais sobre as economias metropolitanas do que as nutrem (pois não servem mais, como no passado, de reservatório de mão-de-obra pouco ou meio qualificada). $\mathrm{Na}$ geografia, como na sociedade em geral, o drama dos pobres é que os ricos precisam cada vez menos deles! É preciso sublinhar, entretanto, a importância dos fluxos da redistribuição, que, pelo viés dos orçamentos do Estado e da Previdência Social, são dirigidos das capitais (zonas de rendas altas) para as periferias, limitando, desse modo, as desigualdades territoriais, que, apesar de tudo, cresceram na última década. Esses fluxos são muito superiores às despesas explícitas do planejamento do território, como os fundos estruturais europeus. 0 emprego público representa um dos mecanismos-chave dessa redistribuição. Na França, numerosas cidades médias dependem fortemente do emprego público direto e dos empregos decorrentes da despesa pública. Tal equilibrio é frágil, e a manutenção dessa solidariedade é uma questão crucial.

Finalmente, duas grandes linhas de reflexão podem ser sugeridas para entender o processo da metropolização que acabamos de descrever. A primeira leva à "economia relacional". Vivemos uma mudança profunda dos modos de produção da riqueza. Estamos passando de uma economia baseada na produtividade de operações, mais ou menos estandardizadas, para uma economia na qual a performance econômica (custo, porém também qualidade, inovação) fundamenta-se na qualidade das relações entre os atores. Esta "economia relacional" diz respeito evidentemente aos serviços propriamente ditos (em que a eficácia está na própria relação), mas também aos setores manufatureiros, nos quais as atividades giram em torno de 
grandes sistemas técnicos cuja fiabilidade depende diretamente da qualidade da comunicação entre os homens. Nessa economia, a divisão do trabalho inspirada no taylorismo - que permitia, por exemplo, separar nitidamente as tarefas da concepção das tarefas da execução, tanto na organização como no espaço - torna-se um obstáculo ao bom desempenho. As reviravoltas permanentes entre atores no seio da firma, entre as próprias firmas e os seus fornecedores, seus clientes e 0 ambiente institucional estão no centro da eficácia, facilitadas por uma geografia compacta (as redes telemáticas ainda têm uma eficácia limitada quando se trata de trocas complexas). A segunda linha diz respeito à "economia da incerteza".

A globalização conduz a um universo econômico cada vez mais imprevisível. As firmas devem ser capazes de reorientar-se muito rapidamente. Quando se pilota um paquete, não é fácil. Daí a irresistível lógica que tende a substituir os paquetes por flotilhas: externalizar, terceirizar, organizar a produção em redes de geometria variável. 0 grande paradoxo é, pois, que a economia moderna clama, ao mesmo tempo, por mais integração e mais desintegração. A empresa vem substituir "redes com valor adicionado", que se fazem e se desfazem de maneira flexível. A metrópole facilita essas mudanças porque funciona como um grande comutador que permite a organização flexível das cadeias produtivas. Constitui também um tipo de "seguro", porque permite às firmas enfrentar as mudanças, apoiando-se em vastos mercados de mão-de-obra e de serviços privados e públicos, e, sobretudo, reduz os preços de saída de uma atividade: hoje é mais fácil fechar uma usina na Île de France do que no Limousin...

\section{Conclusões}

Cabe agora decidir com clareza (cientificamente?) sobre a mundialização, entendida, doravante, como um fenômeno construído. Importa também colocar a sua lógica em perspectiva: não seria um antigo fenômeno amplificado (diferença de grau), de um novo fenômeno (diferença de natureza), de um projeto a realizar ou da extensão de uma tendência observável nos "blocos" do pós-guerra?

Se essas perguntas puderem ser respondidas, é certo que a situação da nossa época será esclarecida. Não é impossível, pois, que o sucesso do termo "mundialização" seja tão grande que ninguém possa entrever, nas condições atuais, a emergência potente de forças que viriam substituir aquilo que está desenvolvendo-se. De uma certa maneira, a ausência de utopia alternativa à celebração da mundialização leva à perda da esperança de qualquer possibilidade de esclarecimento. A "mundialização" funciona enquanto ninguém tem outra coisa a propor. 0 antigo registro da crítica, no qual a perspectiva do "internacional" levava os entusiasmos a uma outra configuração possível, tornou-se, com toda a razão, uma dimensão ultrapassada. Qual será a alternativa?

\section{Epílogo}

Uma citação de Dany COHN-BENDIT (1998): os paises industriais avançados estão descobrindo que o mundo não é feito apenas de consumidores, mas também de produtores. Quando o mercado torna-se mundial, todos os países exigem que sejam tratados em pé de igualdade. Esta posição modifica as relações comerciais internacionais e é inevitável; quanto à mim, digo "Viva a mundialização", porque esta significa que, em outros lugares, as condições de vida melhoram e que a reivindicação do bem-estar não se limita apenas ao perimetro restrito das nações já desenvolvidas. É uma idéia universal. É preciso, pois, repensar a organização do mercado mundial.

\section{Agradecimentos}

Elisabeth Deliège Vasconcelos (tradução); Pedro Vasconcelos (leitura crítica do artigo). 
BENKO, G. (2002) Economics' globalization, world's metropolization. Revista do Departamento de Geografia, n. 15, p. 45-54.

Abstract: Globalization is a fashionable term whose origin is found in literature concerning multinational enterprises. This article shows the diversity of definitions given to this concept according to different branches of knowledge such as economics, geography, history, sociology, communication, or philosophy. The author analyses also its economic aspects and by doing so shows that globalization and metropolization, two concepts often associated, should be used to understand the polarization of the new economics around large cities. As a conclusion this paper shows the necessity of an organized globalization and a regulated worldwide market.

Key words: Globalization; Geographical economy; Social sciences; Metropolization.

Recebido em 23 de julho de 2002; aceito em 31 de agosto de 2002.

\section{Referências bibliográficas}

ANDREFF, W. (1996) Les multinationales globales. Paris, La Découverte. $124 \mathrm{p}$.

BOYER, R.; DEWITTE, P.; GIRAUD, P.-N. et al. (1997) Mondialisation, au-delà des mythes. Paris, La Découverte. $174 \mathrm{p}$.

COHN-BENDIT, D. (1998) Une envie de politique. Paris, La Découverte.

DUNNING, J. (1996) The geographical sources of the competitiveness of firms: some results of a new survey. Transnational Corporations, v. 5, n. 3, p. 1-29.

GIDDENS, A. (1990) The Consequences of modernity. Cambridge, Polity Press.

KEIZER, B.; KENIGSWALD, L. (1996) La triade économique et financière: Amérique du Nord, I'Asie du Sud-Est, Europe de l'Ouest. Paris, Seuil. 368 p.

KRUGMAN, P. (1991a) Geography and trade. Cambridge, MA., MIT Press. $142 \mathrm{p}$.

KRUGMAN, P. (1991b) Increasing returns and economic geography. Journal of Political Economy, n. 99, p. 483-499.

KRUGMAN, P. (1993) First nature, second nature, and metropolitan location. Journal of Regional Science, v. 2, n.33, p.129-144.

KRUGMAN, P. (1994a) Competitiveness: a dangerous obsession. Foreign Affairs, n. 73, p. 28-44.
KRUGMAN, P. (1994b) Complexe landscapes in economic geography. The American Economic Review, v. 2, n.84, p. 412-416.

KRUGMAN, P. (1995) Rendements croissants et géographie économique. In: RALLET, A.; TORRE, A. (eds.) Économie industrielle et économie spatiale. Paris, Economica, p. 317-334.

KRUGMAN, P. (1998a) La mondialisation n'est pas coupable. Paris, La Découverte. $218 \mathrm{p}$.

KRUGMAN, P. (1998b) The accidental theorist. New York, Norton. 204 p.

LEVITT, T. (1983) The globalization of markets. Harvard Business Review, p. 92-103.

MUCCHIELLI, J. L. (1998) Multinationales et mondialisation. Paris, Seuil. 373 p.

OHMAE, K. (1996) De l'État-nation aux États-régions. Paris, Dunod. $214 \mathrm{p}$.

RAINELLI, M. (1997) La nouvelle théorie du commerce internationale. Paris, La Découverte. 128 p.

SASSEN, S. (1991) The global city: New York, London, Tokyo. Princeton, Princeton University Press. 397 p.

VELTZ, P. (1996) Mondialisation, villes et territoires. Paris, PUF. 262 p. 